\title{
Sistem Infomasi Penyewaan Tempat Usaha pada Ogan Permata Indah Mall Jakabaring Palembang
}

\author{
Bella Sestinita $^{1)}$, Suzan Agustri ${ }^{2)}$ \\ ${ }^{1), 2)}$ Program Studi Sistem Informasi Universitas Indo Global Mandiri \\ Jl Jend. Sudirman No. 629 KM. 4 Palembang \\ Email : bellasestinitaa@yahoo.com ${ }^{1)}$, zuzanoid@uigm.ac.id ${ }^{2)}$
}

\begin{abstract}
OPI (Ogan Permata Indah) Jakabaring Mall Palembang is a modern shopping center integrated in the OPI Business Center $(O B C)$ area and not yet maximally in fulfilling information needs and computerized programmed still using manual in the form of Microsoft Word, namely in terms of storing tenant data into the rental archive. All tenants who will rent a business place in Ogan Permata Indah (OPI) Mall, the administration section will look for the tenants 'data which will require a long time because the tenants' data has not been well integrated. So this research will make an information system for leasing business places in Ogan Permata Indah (OPI), Jakabaring Mall, Palembang. Researchers use the Microsoft Access 2007 database, with applications using Visual Basic 6.0. Using this application can improve performance in managing better business place rental data and this system is expected to facilitate both tenants and the administration in managing the rental process.
\end{abstract}

Keywords : Information system, Sistem Informasi, Business Rental, Waterfall, Visual Basic 6.0

\begin{abstract}
Abstrak
OPI (Ogan Permata Indah) Mall Jakabaring Palembang merupakan sebuah pusat perbelanjaan modern yang terintegrasi dalam kawasan OPI Business Center $(O B C)$. dan belum secara maksimal dalam memenuhi kebutuhan informasi dan terprogram secara komputerisasi masih menggunakan manual berupa Microsoft Word. Yaitu dalam hal penyimpanan data penyewa kedalam arsip penyewaan. Belum terintegrasi sehingga apabila terdapat penyewa yang akan menyewa tempat usaha pada Ogan Permata Indah (OPI) Mall, bagian administrasi akan mencari datadata penyewa tersebut yang nantinya membutuhkan waktu yang lama karena data-data penyewa belum terintegrasi dengan baik. Maka saya akan membuat suatu sistem informasi penyewaan tempat usaha pada Ogan Permata Indah (OPI) Mall Jakabaring Palembang. Peneliti menggunakan database Microsoft Access 2007, dengan aplikasi menggunakan Visual basic 6.0. Menggunakan aplikasi ini dapat meningkatkan kinerja dalam mengelola data penyewaan tempat usaha yang lebih baik dan sistem ini diharapkan dapat mempermudah baik penyewa maupun bagian administrasi dalam mengelola proses penyewaan.
\end{abstract}

Kata kunci : Sistem Informasi, Penyewaan tempat Usaha, Waterfall, Visual Basic 6.0 


\section{Pendahuluan}

Teknologi merupakan sebuah kata yang saat ini telah dijadikan oleh semua kalangan masyrakat sebagai tolak ukur dalam melakukan semua kegiatan sehari-hari. Misalnya saja penggunaan teknologi komputer, yang dijadikan sebuah kebutuhan yang mendasar bagi sebagian masyarakat. Komputer memiliki banyak manfaat yang bisa didapatkan oleh masyarakat seperti membantu mengerjakan semua pekerjaan kantor, membantu dalam proses mendapatkan informasi penting dan lain sebagainya. Teknologi akan semakin bermanfaat jika ditambah dengan sebuah aplikasi yang dapat memberikan informasi bagi masyarakat ataupun bagi kalangan perusahaan. Informasi tersebut dapat dijadikan sebuah kebutuhan ataupun tolak ukur untuk melakukan semua kegiatan operasional perusahaan, misalnya dalam melakukan proses pendataan bisnis, dapat menggunakan aplikasi yang khusus mengelola data bisnis tersebut. Semua perusahaan dapat menggabungkan antara teknologi dan informasi menjadi sebuah kesatuan, dalam hal ini menjadikan teknologi informasi yang dapat menghasilkan tentang laporan penjualan, laporan persediaan barang ataupun laporan bisnis lainnya, Salah satu perusahaan yang ingin memanfaatkan teknologi informasi tersebut adalah OPI Mall. Ogan Permata Indah (OPI) Mall adalah sebuah pusat perbelanjaan modern yang terintegrasi dalam kawasan OPI Business Center (OBC). Bangunan pusat perbelanjaan Mall OPI dikembangkan diatas lokasi berjumlah 4 lantai. Dalam bangunan mall tersebut selain terdapat bangunan ruang ritel beserta fasilitasnya, juga terdapat ruang parkir indoor. Adapun luas total bangunan adalah $+/-89.211,56 \mathrm{~m}^{2}$.

Lingkup permasalahan penelitian ini mencakup sebagai berikut:

1. Pengolahan Data Penyewa

2. Pengolahan Data Ruangan

3. Pengolahan Proses Pembayaran

4. Laporan Data Penyewa

5. Laporan Data Ruangan

6. Laporan Data Pembayaran

Tujuan utama dari metode penelitian ini adalah:

Agar data penyewaan yang sedang diproses, maupun yang telah selesai diproses dapat dicari dengan cepat. Merancang sistem informasi penyewaan tempat usaha pada Ogan Permata Indah (OPI) Mall Jakabaring Palembang dalam mengatasi pencarian data konsumen dan data penyewaan tempat. Pembuatan laporan laporan, penyimpanan data dan keamanan data menjadi lebih efektif dan efisien.

Manfaat dari penyusunan penelitian ini apabila program yang dibuat untuk sistem informasi penyewaan tempat usaha pada Ogan Permata Indah (OPI) Mall Jakabaring Palembang adalah sebagai berikut :

1. Dapat memberikan layanan informasi yang maksimal kepada konsumen.

2. Meningkatkan pengolahan data yang lebih akurat dan efisien.
3. Mempermudah proses pendataan yang sedang diproses, maupun yang telah selesai diproses agar peningkatan pencarian data dapat dilakukan dengan cepat.

\section{A. Sistem}

Secara sederhana, suatu sistem dapat diartikan sebagai suatu kumpulan atau himpunan dari unsur, komponen, atau variabel yang terorganisir, saling berinteraksi, saling bergantung satu sama lain, dan terpadu (Tata Sutabri, 2012).

\section{B. Informasi}

Informasi adalah kumpulan data yang diolah menjadi bentuk yang lebih berguna dan lebih berarti bagi yang menerima (Jogiyanto, 2005).

\section{Sistem Informasi}

Sistem informasi adalah suatu sistem di dalam suatu organisasi yang mempertemukan kebutuhan pengolahan transaksi harian, mendukung operasi, bersifat manajerial dan kegiatan strategi dari suatu organisasi dan menyediakan pihak luar tertentu dengan laporan-laporan yang diperlukan (Jogjyanto, 2005).

\section{Penyewaan}

Penyewaan adalah setiap kegiatan pembiayaan perusahaan dalam bentuk penyediaan barang modal untuk digunakan oleh suatu perusahaan selama jangka waktu tertentu berdasarkan pembayaran-pembayaran secara berkala disertai hak pilih bagi perusahaan tersebut untuk membeli barang modal yang bersangkutan atau memperpanjang jangka waktu penyewaan berdasarkan nilai sisa yang telah disepakati bersama (Sawir, 2004).

\section{E. Mall}

Mall adalah jenis dari pusat perbelanjaan yang secara arsitektur berupa bangunan tertutup dengan suhu yang diatur dan memiliki jalur untuk berjalan-jalan yang teratur sehingga berada diantara toko-toko yang saling berhadapan ( Machfoedz, 2006;108).

\section{F. Metode Waterfall}

Pengembangan sistem didefinisikan sebagai aktivitas untuk menghasilkan sistem informasi berbasis komputer untuk menyelesaikan persoalan (problem) organisasi atau memanfaatkan kesempatan (opportunities) yang timbul. (waterfall) biasa juga disebut siklus hidup perangkat lunak. Mengambil kegiatan dasar seperti spesifikasi, pengembangan, validasi, dan evolusi dan mempresentasikannya sebagai fase-fase proses yang berbeda seperti spesifikasi persyaratan,perancangan perangkat lunak, implementasi, pengujian dan seterusnya. Secara umum tahapan pada model waterfall dapat dilihat pada gambar berikut (Jogiyanto H.M, 2010). 


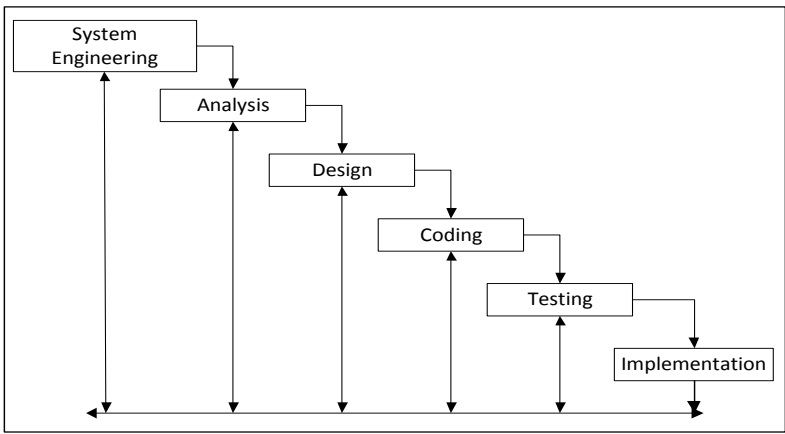

Gambar 1. Tahapan Pengembangan Waterfall

Tahapan - tahapan dalam pengembangan Waterfall sebagai berikut ini :

1. System Engineering

Pada tahap System Engineering atau Rekayasa Perangkat Lunak diawali dengan mencari kebutuhan dari keseluruhan sistem yang akan diaplikasikan kedalam bentuk software. Hal ini sangat penting, mengingat software harus dapat berinteraksi dengan elemen-elemen yang lain seperti hardware, database, dsb. Tahap ini sering disebut dengan project definition.

2. Analisis

Dalam langkah ini merupakan analisa terhadap kebutuhan sistem. Pengumpulan data dalam tahap ini bisa melakukan sebuah penelitian, wawancara atau study literatur. Seorang sistem analisis akan menggali informasi sebanyak-banyaknya dari user sehingga akan tercipta sebuah sistem komputer yang bisa melakukan tugas-tugas yang diinginkan oleh user tersebut. Tahapan ini menghasilkan dokumen user requirement atau bisa dikatakan sebagai data yang berhubungan dengan keinginan user dalam pembuatan sistem. Dokumen inilah yang akan menjadi acuan sistem analisis untuk menterjemahkan kedalam bahasa pemrograman.

3. Design

Proses Design (Perancangan) akan menterjemahkan syarat kebutuhan ke sebuah perancangan perangkat lunak yang dapat diperkirakan sebelum dibuat koding. Proses ini berfokus pada : struktur data, arsitektur perangkat lunak, representasi interface, dan detail (algoritma) prosedural.

\section{Coding}

Untuk dapat dimengerti oleh mesin, dalam hal ini adalah komputer, maka design tadi harus diubah bentuknya menjadi bentuk yang dapat dimengerti oleh mesin, yaitu kedalam bahasa pemrograman melalui proses coding. Tahap ini merupakan implementasi dari tahap design yang secara teknis nantinya dikerjakan oleh programmer. Asalkan dokumen yang disebut software requirement. Dokumen inilah yang akan digunakan programmer untuk melakukan aktivitas pembuatan sistemnya.

\section{G. System Engineering}

System Engineering adalah aktivitas untuk menetapkan kebutuhan-kebutuhan pada tingkat sistem kemudian mengalokasikan beberapa bagian dari kebutuhan-kebutuhan tersebut ke satu atau beberapa komponen rekayasa.

\section{Pembahasan}

\section{A. Diagram Konteks Sistem Usulan}

Diagram konteks (Context Diagram) atau level 0 merupakan level tertingi dari DFD yang menggambarkan seluruh input atau output dari sistem, jadi Diagram Konteks menggambarkan keseluruhan sistem.

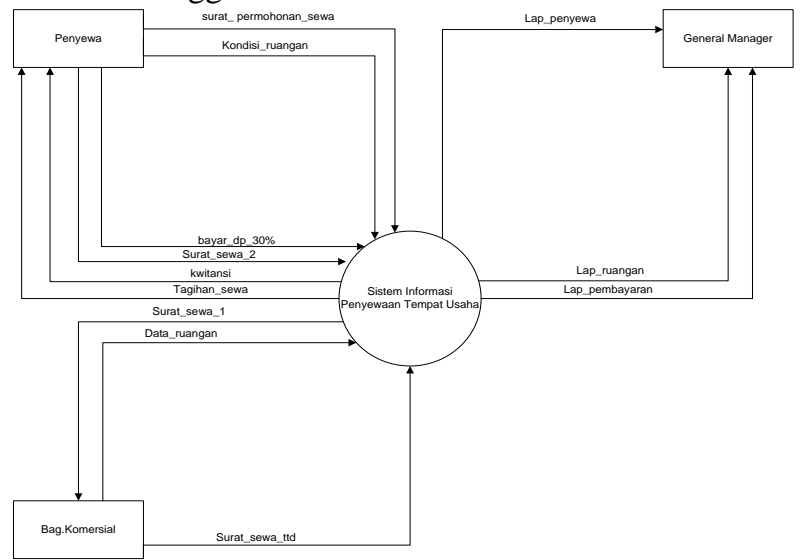

Gambar 2. Diagram Konteks Sistem Informasi Penyewaan Tempat Usaha pada Ogan Permata Indah (OPI) Mall Jakabaring Palembang

\section{Diagram Nol Sistem Usulan}

Diagram nol menggambarkan hubungan aliran data dengan entitas, data store dan proses yang terjadi didalamnya. Diagram nol sistem yang baru pada Sistem Informasi Penyewaan Tempat Usaha pada Ogan Permata Indah (OPI) Mall Jakabaring Palembang.

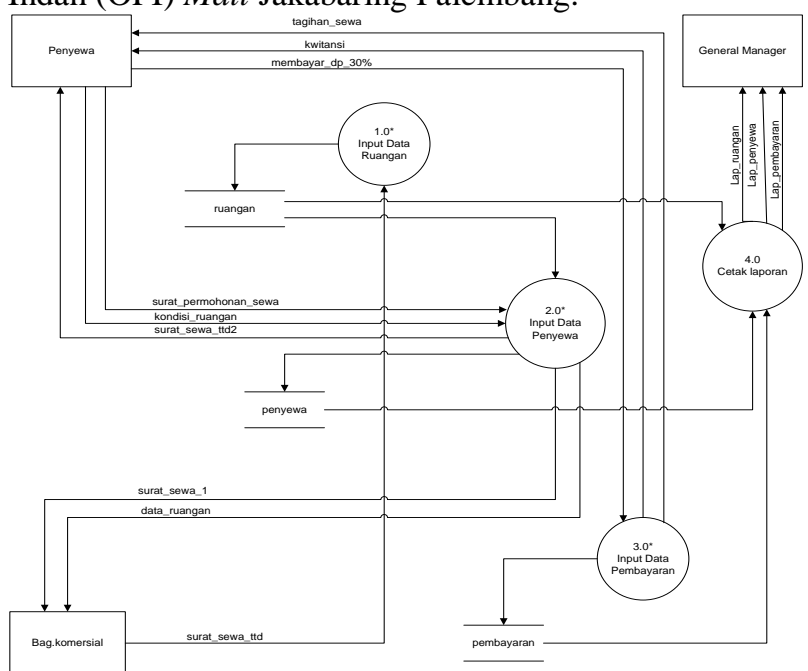

Gambar 3. Diagram Nol Sistem Informasi Penyewaan Tempat Usaha pada Ogan Permata Indah (OPI) Mall Jakabaring Palembang

2. Diagram Rinci Proses 4.0 Laporan

Diagram rinci proses cetak laporan sistem informasi penyewaan tempat usaha pada Ogan Permata Indah (OPI) Mall Jakabaring Palembang. 


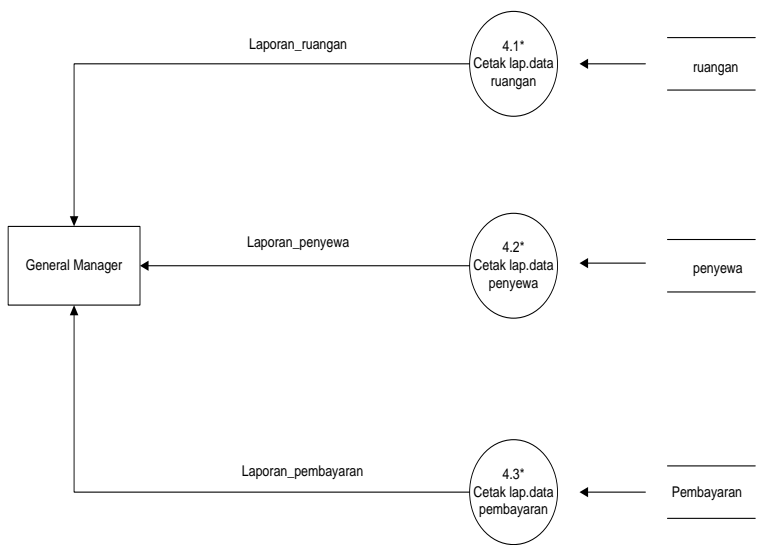

Gambar 4. Diagram Rinci 4.0 Cetak Laporan Sistem Informasi Penyewaan Tempat Usaha pada Ogan Permata Indah (OPI) Mall Jakabaring Palembang

\section{B. Entity Relationship Diagram}

ERD yang dibuat didalam Sistem Informasi Penyewaan Tempat Usaha pada Ogan Permata Indah (OPI) Mall Jakabaring Palembang yaitu sebagai berikut:

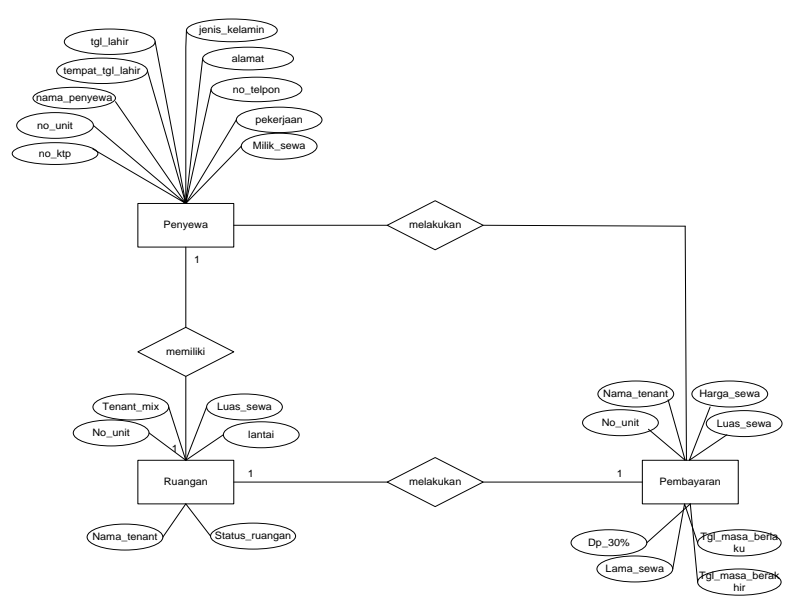

Gambar 5. ERD Sistem Informasi Penyewaan Tempat Usaha pada Ogan Permata Indah (OPI) Mall Jakabaring Palembang

C. Tampilan Layar Aplikasi

1. Tampilan Menu Utama

Tampilan Menu Utama adalah kumpulan tabel - tabel data pemesanan dan penjualan rumah yang isi sesuai dengan kebutuhan.

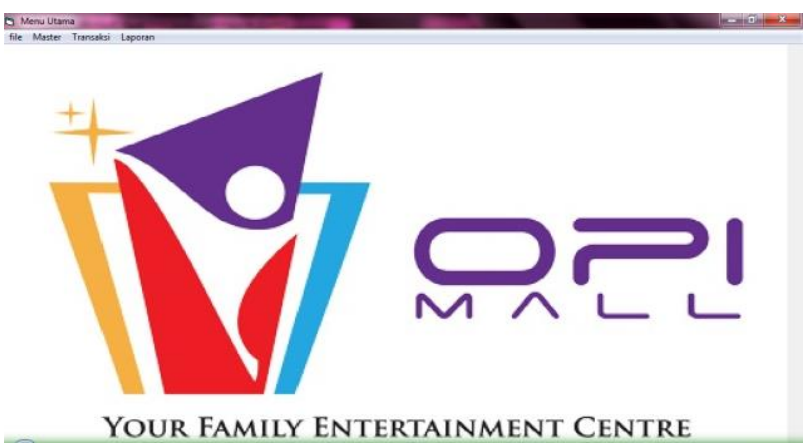

Gambar 6. Tampilan Menu Utama
2. Menu Data Penyewa

Tampilan menu data data penyewa, merupakan form untuk manambah data penyewa yang tersedia di Ogan Permata Indah (OPI) mall, isi data terdiri dari no sewa, nama penyewa, no ktp, tempat tanggal lahir, tanggal lahir, jenis kelamin, alamat lengkap, no telpon, pekerjaan.

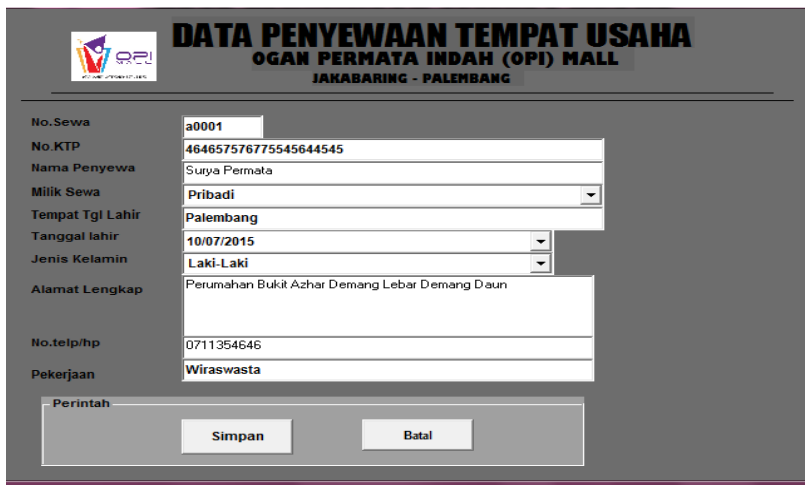

Gambar 7. Tampilan Data Penyewa

3. Menu Data Ruangan

Menu data perumahan merupakan Tampilan Layar Form Data Penyewa, merupakan form untuk mengubah data penyewa yang tersedia di Ogan Permata Indah (OPI) mall, isi data terdiri dari no unit, tenant mix, nama tenant, luas sewa, lantai, status ruangan.

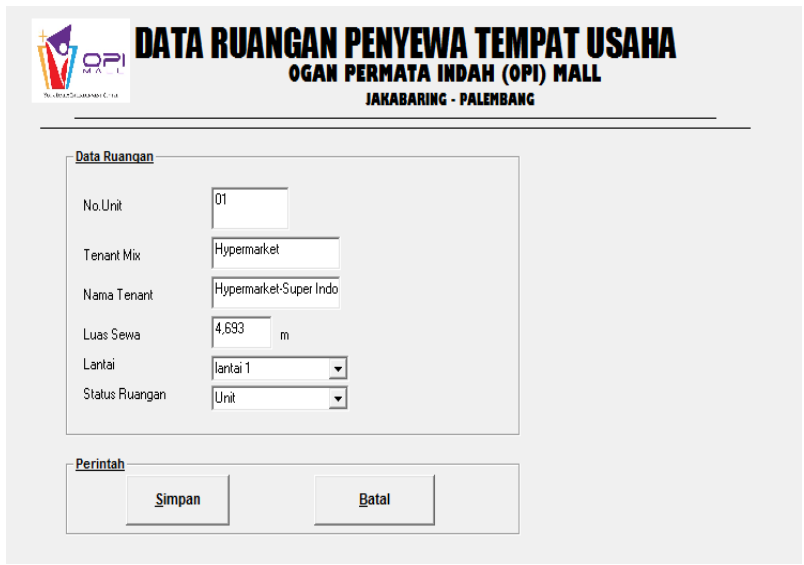

Gambar 8. Tampilan Data Ruangan

4. Menu Data Rumah

Menu data rumah merupakan tampilan layar form tambah transaksi pembayaran, merupakan form untuk manambah data pembayaran yang tersedia di Ogan Permata Indah (OPI) mall, isi data terdiri dari no sewa, tanggal bayar, nama tenant, nama penyewa, harga sewa, dp sewa $30 \%$, luas sewa, lama sewa, total pembayaran, tanggal masa berlaku, tanggal masa berakhir. 


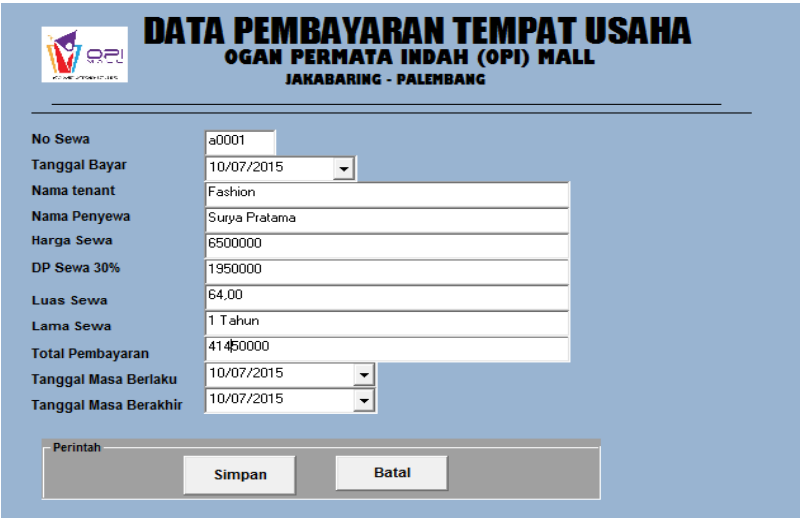

Gambar 9. Tampilan Data Pembayaran

\section{Menu Laporan Penyewaan}

Menu Data Tampilan Layar Form Entry Laporan Data Penyewa, merupakan form untuk mangentri data penyewa yang tersedia di Ogan Permata Indah (OPI) mall, isi data terdiri dari no sewa, nama penyewa, no ktp, tempat tanggal lahir, tanggal lahir, jenis kelamin, alamat lengkap, no telpon, pekerjaan.

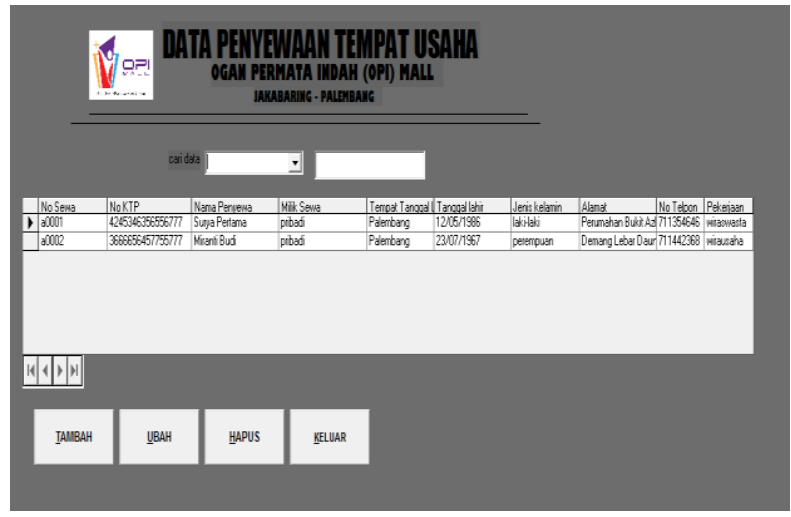

Gambar 10. Tampilan Laporan Penyewaan

6. Menu Laporan Ruangan

Menu Data Tampilan Layar Form Entry Laporan Data Penyewa, merupakan form untuk mangentri data penyewa yang tersedia di Ogan Permata Indah (OPI) mall, isi data terdiri dari no unit, tenant mix, nama tenant, luas sewa, lantai, status ruangan.

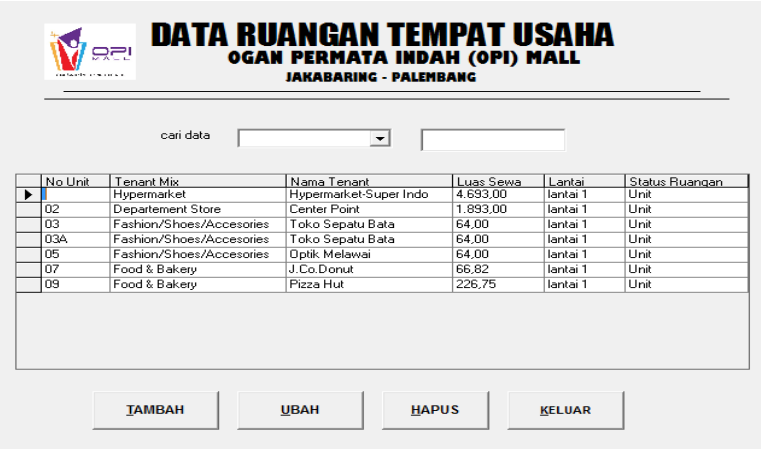

Gambar 11. Tampilan Laporan Ruangan

\section{Menu Laporan Pembayaran}

Menu Data Tampilan Layar Form Entry Laporan transaksi pembayaran, merupakan form untuk mangentri data pembayaran yang tersedia di Ogan Permata Indah (OPI) mall, isi data terdiri dari no sewa, tanggal bayar, nama tenant, nama penyewa, harga sewa, dp sewa $30 \%$, luas sewa, lama sewa, total pembayaran, tanggal masa berlaku, tanggal masa berakhir.

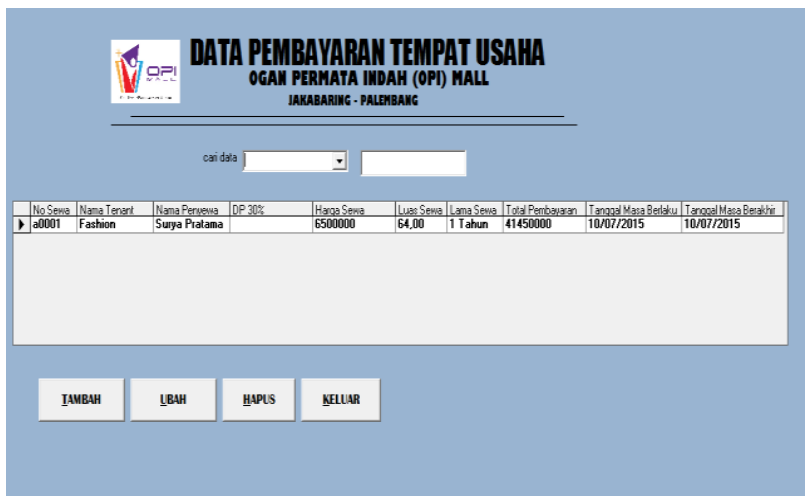

Gambar 12. Tampilan Laporan Pembayaran

D. Coding

1. Bahasa Pemrograman Visual Basic 6.0

Visual Basic adalah bahasa pemrograman yang digunakan untuk membuat aplikasi Windows yang berbasis grafis (GUI- Graphical User Interface).Bahasa Basic itu sendiri diciptakan oleh Professor John Kemeny dan Thomas Eugene Kurtz dari Perguruan Tinggi Dartmouth pada pertengahan tahun 1960-an.[1]. Microsoft Visual Basic adalah Bahasa Pemrograman yang digunakan untuk membuat aplikasi windows yang berbasis grafis (GUI - Graphical User Interface).

[2]. Beberapa keuntungan menggunakan Visual Basic Pemrograman berbasis grafik $(G U I=$ Graphical User Interface) sehingga pembuatan program aplikasi menjadi lebih mudah dan nyaman. Pembuatan penempatan antar muka (Inteface) hanya membangun objek di layar monitor, tanpa harus menuliskan kode program yang panjang dan rumit [3]. Basis Bahasa Pemrograman menggunakan BASIC (Beginners All Purpose Symbolic Instruction Code), Yakni salah satu Bahasa Pemrograman yang cukup sederhana dan mudah dipelajari.[4]. Visual Basic menyediakan perangkat yang dapat digunakan untuk membuat program aplikasi baik aplikasi kecil dan sederhana untuk keperluan sendiri.

\section{Microsoft Access 2007}

Microsoft Access 2007 adalah suatu program aplikasi basis data komputer relasional yang digunakan untuk merancang, membuat dan mengolah.

\section{Kesimpulan}

Berdasarkan pembahasan dan uraian pada bab sebelumnya mengenai pembuatan Sistem Informasi Pengolahan Data Penyewaan tempat usaha pada Ogan Permata Indah (OPI) Mall Jakabaring Palembang, maka 
penelitian membuat beberapa kesimpulan sebagai berikut:

1. Penelitian ini menghasilkan sebuah aplikasi penyewaan tempat usaha dengan menggunakan bahasa pemprograman Visual basic 6.0 dan Microsoft Access 2007 sebagai Databasenya.

2. Dengan adanya aplikasi ini mempermudah pihak perusahaan dalam mengontrol penyewaan tempat usaha dan juga mempermudah melakukan proses pengolahan data penyewaan tempat usaha secara efektif dalam pencarian data.

3. Memberikan masukkan kepada Ogan Permata Indah (OPI) Mall Jakabaring Palembang mengenai sistem baru yang akan diterapkan sehingga dapat memperoleh informasi yang tepat.

\section{Daftar Pustaka}

Agnes, Sawir, 2004. Analisis Kinerja Keuangan dan Perencanaan Keuangan Perusahaan, Jakarta : PT. Gramedia Pustaka Utama.

Jogiyanto, HM. 2005. Analisis dan design Sistem Informasi Pendekatan Terstruktur dan Aplikasi Bisnis Edisi pertama Cetakan ke 4. Andi. Jogyakarta, Indonesia.

Jogiyanto, HM. 2010. Pengenalan Komputer. Andi, :Yogyakarta.

Machfoedz, Mahmud, 2006. Kewirausahaan : Metode, Manajemen, dan Implementasi. Yogyakarta : BPFE - Yogyakarta.

Sutabri,Tata, 2012. Sistem Information Manajemen. Penerbit Andi: Yogyakarta. 